\title{
PEMODELAN METODE BROWN'S DOUBLE EXPONENTIAL SMOOTHING (B-DES) DAN BROWN'S WEIGHTED EXPONENTIAL MOVING AVERAGE (B-WEMA) MENGGUNAKAN OPTIMASI LEVENBERG-MARQUARDT PADA JUMLAH WISATAWAN DI JAWA TENGAH
}

\author{
Dilla Retno Deswita ${ }^{1}$, Abdul Hoyyi ${ }^{2}$, Tatik Widiharih ${ }^{3}$ \\ 1,2,3 Departemen Statistika, Fakultas Sains dan Matematika, Universitas Diponegoro \\ dilladesw@gmail.com
}

\begin{abstract}
The tourism sector is one of the national development priority sectors because it contributes to foreign exchange earnings, the development of business areas, and the absorption of investment and labor. In 2018 the tourism sector will become the second largest foreign exchange earner after oil palm. Foreign exchange contributed by the tourism sector in 2018 was US $\$ 19.29$ billion, an increase of $15.4 \%$. The increase in contributions was driven by an increase in the number of foreign tourist arrivals by $12.58 \%$, domestic tourists by $12.37 \%$, and from investment. Therefore it is necessary to study the forecasting of the number of tourists after seeing the great potential generated from the tourism sector. The data forecast is data on the number of tourists in Central Java, both foreign and domestic data. Both data shows the tendency of an upward trend pattern. So that both data can be analyzed using B-DESmethods (Brown's Double Exponential Smoothing) and B-WEMA (Brown's Weighted Exponential Moving Average)that are optimized with LM (Levenberg-Marquardt). Both methods are able to analyze trend patterned data without assumptions making it easier in the analysis process. In addition, the two methods in previous studies were able to produce a small forecasting accuracy. The MAPE (Mean Absolute Percentage Error) value out sample is used to compare the forecasting results of the two methods. The results of the implementation of LM optimization on the data of the number of domestic tourists obtained the optimal parameter value of the B-DES method is 0.21944386 with MAPE out sample $16.26516 \%$ and B-WEMA method is 0.219441 with MAPE out sample $16.26515 \%$. While the data on the number of foreign tourists obtained the optimal parameter value of the B-DES method was 0.26213368 with the MAPE out of the sample $23.61278 \%$ and the B-WEMA method was 0.26213367 with the MAPE out the sample $23.61278 \%$. This means that both methods have a good level of forecasting accuracy in the data on the number of domestic tourists and an adequate level of accuracy in the data on the number of foreign tourists.
\end{abstract}

Keywords : B-DES, B-WEMA, Levenberg-Marquardt, Tourists in Central Java

\section{PENDAHULUAN}

Sektor pariwisata nasional memiliki peranan yang sangat penting dalam perkembangan dan kontribusinya terhadap penerimaan devisa, pengembangan wilayah dan usaha, serta penyerapan investasi dan tenaga kerja yang tersebar di berbagai wilayah di Indonesia. Perkembangan pariwisata dapat dilihat dari banyaknya kunjungan wisatawan baik wisatawan mancanegara maupun nusantara. Apabila sektor pariwisata tumbuh dan berkembang dengan baik maka akan menjadi penunjang lajunya pembangunan suatu wilayah. Melihat potensi besar yang dihasilkan sektor pariwisata maka perlu dilakukan studi yang mendalam mengenai peramalan jumlah wisatawan mancanegara dan nusantara menggunakan data yang terbentuk dari waktu ke waktu atau yang disebut data runtun waktu.

Salah satu metode analisis runtun waktu yang banyak digunakan untuk peramalan adalah metode moving average. Jenis metode rata-rata bergerak yang paling sederhana adalah Simple Moving Average (SMA), dimana hasil peramalan yang diperoleh dari data baru akan berubah-ubah. Weighted Moving Average (WMA) merupakan peningkatan dari metode SMA dimana memberikan nilai bobot yang berbeda untuk setiap data. Tipe moving average lainnya adalah Exponential Moving Average (EMA) yang merupakan variasi dari 
metode SMA dimana dalam pembentukan faktor bobot dalam analisis data runtun waktu menggunakan bilangan eksponensial.

Pada penelitian sebelumnya, Hansun telah memperkenalkan pendekatan baru metode moving average yang menggabungkan metode WMA dan EMA (Hansun, 2013). Pendekatan ini disebut sebagai Weighted Exponential Moving Average (WEMA) dimana didapatkan kesimpulan bahwa metode WEMA menghasilkan nilai MSE dan MAPE terkecil dibanding dengan metode moving average lainnya. Selanjutnya Hansun memperkenalkan metode baru yang menggabungkan WMA dan Brown's Double Exponential Smoothing (B-DES) disebut Brown's Weighted Exponential Moving Average (B-WEMA) (Hansun, 2016).

Pada penilitian ini, para penulis akan menggabungkan optimasi dengan B-DES dan B-WEMA yang kemudian akan dibandingkan hasil peramalannya. Metode yang diusulkan akan diterapkan pada data bulanan jumlah wisatawan nusantara dan mancanegara yang berkunjung ke daya tarik wisata Jawa Tengah pada tahun 2012 hingga 2018.

\section{TINJAUAN PUSTAKA}

\subsection{Weighted Moving Average (WMA)}

Metode WMA adalah metode yang memberikan nilai bobot yang berbeda pada setiap dimana data yang terakhir merupakan data yang paling relevan untuk peramalan sehingga diberi bobot yang lebih besar. Bobot ditentukan sedemikian rupa sehingga jumlah peluang pembobotnya adalah sama dengan satu. Rumus metode WMA sebagai berikut:

$$
W M A=\frac{T X_{n}+(T-1) X_{n-1}+\cdots+2 X_{n-T+2}+X_{n-T+1}}{T+(T-1)+\cdots+2+1}
$$

dengan $\mathrm{T}$ banyaknya periode atau rentang bilangan peramalan, $X_{n}$ nilai data deret waktu pada titik $n$.

\subsection{Brown's Double Exponential Smoothing (B-DES)}

Metode ini dapat diterapkan pada data yang memiliki pola trend. Perbedaan dari metode smoothing adalah keakuratan hasil ramalan tergantung pada parameter pemulusan (parameter beta) yang dapat memperbaiki trend. Sehingga parameter beta optimal sangat diperlukan, parameter beta dapat dioptimalkan menggunakan algoritma LevenbergMarquardt dalam software R. Persamaan yang digunakan pada metode Brown adalah sebagai berikut (Makridakis et al., 1993):

Persamaan statistik smoothing pertama (single):

$$
S_{n}^{\prime}=\beta X_{n}+(1-\beta) S_{n-1}^{\prime} \quad \mathrm{n}=2,3, . . \mathrm{k}
$$

$\beta$ diestimasi secara numerik dengan metode Levenberg-Marquardt

Persamaan statistik smoothing kedua (double):

$$
S_{n}^{\prime \prime}=\beta S_{n}^{\prime}+(1-\beta) S_{n-1}^{\prime \prime} \quad \mathrm{n}=2,3, . . \mathrm{k}
$$

Kemudian, peramalan $\mathrm{m}$ periode ke depan ditulis dengan $F_{n+m}$, untuk $\mathrm{m} \geq 1$,

$$
F_{n+m}=a_{n}+b_{n} m
$$


dengan $a_{n}$ merupakan nilai pemulusan eksponensial pertama dan kedua pada saat $\mathrm{n}, b_{n}$ merupakan nilai pemulusan trend pada saat $\mathrm{n}$

$$
\begin{gathered}
a_{n}=S_{n}^{\prime}+\left(S_{n}^{\prime}-S_{n}^{\prime \prime}\right)=2 S_{n}^{\prime}-S_{n}^{\prime \prime} \\
b_{n}=\frac{\beta}{1-\beta}\left(S_{n}^{\prime}-S_{n}^{\prime \prime}\right)
\end{gathered}
$$

Penggunaan rumus (2) dan (3) agar dapat digunakan maka nilai $S_{n-1}^{\prime}$ dan $S_{n-1}^{\prime \prime}$ harus tersedia. Pada saat $n=2$, untuk nilai $S_{1}^{\prime}$ dan $S_{1}^{\prime \prime}$ menggunakan nilai rata-rata dari beberapa nilai pertama sebagai titik awal (Makridakis et al., 1999).

\subsection{Brown's Weighted Exponential Moving Average (B-WEMA)}

Metode B-WEMA merupakan metode penyempurnaan dari metode Weighted Exponential Moving Average (WEMA) yang telah diperkenalkan pada tahun 2013. Perbedaan utama pada kedua metode tersebut adalah metode WEMA menggabungkan perhitungan faktor pembobotan pada metode Weighted Moving Average (WMA) dengan Exponential Moving Average (EMA), sedangkan pada metode B-WEMA menggabungkan perhitungan faktor pembobotan pada metode WMA dengan Brown's Double Exponential Smoothing (B-DES). Metode B-WEMA dapat diterapkan untuk meramalkan nilai data deret waktu dimasa mendatang dengan pola trend. Berikut merupakan prosedur perhitungan BWEMA (Hansun, 2016):

1. Menghitung nilai dasar $\left(B_{n}\right)$ yang merupakan moving average dari $\mathrm{n}$ data dengan menggunakan persamaan WMA untuk data dan periode waktu tertentu.

$$
B_{n}=\frac{T X_{n}+(T-1) X_{n-1}+\cdots+2 X_{n-T+2}+X_{n-T+1}}{T+(T-1)+\cdots+2+1}
$$

2. Dengan menggunakan nilai dasar yang telah didapatkan, kemudian menghitung nilai peramalan dengan persamaan sebagai berikut, dimana

$$
B_{n}=S_{n-1}^{\prime}=S_{n-1}^{\prime \prime}
$$

Persamaan statistik smoothing pertama (single):

$$
S_{n}^{\prime}=\beta X_{n}+(1-\beta) S_{n-1}^{\prime}
$$

$\beta$ diestimasi secara numerik dengan metode Levenberg-Marquardt

Persamaan statistik smoothing kedua (double):

$$
S_{n}^{\prime \prime}=\beta S_{n}^{\prime}+(1-\beta) S_{n-1}^{\prime \prime}
$$

Kemudian, peramalan $\mathrm{m}$ periode ke depan ditulis dengan $F_{n+m}$, untuk $\mathrm{m} \geq 1$,

$$
F_{n+m}=a_{n}+b_{n} m
$$

dengan $a_{n}$ merupakan nilai pemulusan eksponensial pertama dan kedua pada saat $\mathrm{n}, b_{n}$ merupakan nilai pemulusan trend pada saat $\mathrm{n}$

$$
a_{n}=S_{n}^{\prime}+\left(S_{n}^{\prime}-S_{n}^{\prime \prime}\right)=2 S_{n}^{\prime}-S_{n}^{\prime \prime}
$$




$$
b_{n}=\frac{\beta}{1-\beta}\left(S_{n}^{\prime}-S_{n}^{\prime \prime}\right)
$$

\subsection{Levenberg-Marquardt}

Metode Levenberg-Marquardt merupakan salah satu metode optimasi untuk menyelesaikan masalah kuadrat terkecil yang didasarkan pada metode Gauss-Newton. Pada metode Levenberg-Marquadt, arah turun ditentukan dengan mempertimbangkan parameter damping yang akan mempengaruhi arah dan juga besar langkah (Budiasih, 2009). Pada dasarnya algoritma Levenberg-Marquardt adalah meminimalkan jumlah residual kuadrat terboboti antara data yang diukur dengan fungsi kurva.Ukuran nilai residual ini disebut dengan kriteria galat chi-kuadrat, yaitu (Gavin, 2019):

$$
\begin{aligned}
\chi^{2}(\beta) & =\sum_{i=1}^{m}\left[\frac{y\left(t_{i}\right)-\hat{y}\left(t_{i} ; \beta\right)}{w_{i}}\right]^{2} \\
& =(\boldsymbol{y}-\widehat{\boldsymbol{y}}(\boldsymbol{\beta}))^{T} \boldsymbol{W}(\boldsymbol{y}-\widehat{\boldsymbol{y}}(\boldsymbol{\beta})) \\
& =\boldsymbol{y}^{\boldsymbol{T}} \boldsymbol{W} \boldsymbol{y}-2 \boldsymbol{y}^{\boldsymbol{T}} \boldsymbol{W} \hat{\boldsymbol{y}}+\widehat{\boldsymbol{y}}^{\boldsymbol{T}} \boldsymbol{W} \widehat{\boldsymbol{y}}
\end{aligned}
$$

dengan nilai $w_{i}$ merupakan ukuran bobot untuk setiap galat dari $y\left(t_{i}\right)$. Sedangkan matriks W merupakan matriks diagonal dengan $W_{i i}=1 / \mathrm{m}$ dimana $\mathrm{m}$ adalah banyaknya data. Apabila fungsi $\hat{y}(t ; \beta)$ adalah non linier, maka untuk meminimalkan $\chi^{2}$ dilakukan secara iteratif.

Pada metode Gradient Decscent, nilai gradient dari fungsi objektif chi-kuadrat didefinisikan sebagai berikut:

$$
\begin{aligned}
\frac{\partial}{\partial_{\beta}} \chi^{2} & =2(\boldsymbol{y}-\widehat{\boldsymbol{y}}(\boldsymbol{\beta}))^{T} \boldsymbol{W} \frac{\partial}{\partial_{\beta}}(\boldsymbol{y}-\widehat{\boldsymbol{y}}(\boldsymbol{\beta})) \\
& =-2(\boldsymbol{y}-\widehat{\boldsymbol{y}}(\boldsymbol{\beta}))^{T} \boldsymbol{W}\left[\frac{\partial \widehat{\boldsymbol{y}}(\boldsymbol{\beta})}{\partial \boldsymbol{\beta}}\right] \\
& =-2(\boldsymbol{y}-\widehat{\boldsymbol{y}})^{T} \boldsymbol{W} \boldsymbol{J}
\end{aligned}
$$

dimana $m \times 1$ matriks Jacobian yaitu $[\partial \hat{y}(\beta) / \partial \beta]$ mewakili sensitivitas lokal dari fungsi $\hat{y}(t ; \beta)$ untuk variasi dalam parameter $\beta$. Pembaharuan parameter $h$ yang bergerak ke arah yang semakin mengecilkan nilai $\chi^{2}$ adalah sebgai berikut:

$$
\boldsymbol{h}_{\boldsymbol{g d}}=\alpha \boldsymbol{J}^{\boldsymbol{T}} \boldsymbol{W}(\boldsymbol{y}-\widehat{\boldsymbol{y}})
$$

dimana nilai skalar positif $(\alpha)$ menentukan panjang langkah pada metode Gradient Descent. $\boldsymbol{J}^{\boldsymbol{T}}$ merupakan transpose matriks Jacobian yang berdimensi $1 \times \mathrm{m}$, W merupakan matriks diagonal dengan $W_{i i}=1 / m$ yang berdimensi $m \times m$, dan $(\boldsymbol{y}-\widehat{\boldsymbol{y}})$ merupakan matriks dengan dimensi $m \times 1$.

Persamaan untuk pembaharuan $h$ pada metode Gauss-Newton adalah sebagai berikut:

$$
\left[J^{T} W J\right] h_{g n}=J^{T} W(y-\widehat{y})
$$


Pembaharuan parameter dari algoritma Levenberg-Marquardt (LM) mengadopsi dari metode gradient descent dan Gauss-Newton. Adapun langkah $\mathbf{h}_{1 \mathrm{~m}}$ ditentukan dengan memodifikasi persamaan (17), yaitu

$$
\begin{aligned}
{\left[\boldsymbol{J}^{T} \boldsymbol{W}+\lambda \boldsymbol{I}\right] \boldsymbol{h}_{\boldsymbol{l m}}=\boldsymbol{g} \text { dengan } \boldsymbol{g} } & =\boldsymbol{J}^{\boldsymbol{T}} \boldsymbol{W}(\boldsymbol{y}-\widehat{\boldsymbol{y}}) \text { dan } \lambda \geq 0 \text { atau } \\
{\left[\boldsymbol{J}^{\boldsymbol{T}} \boldsymbol{W} \boldsymbol{J}+\lambda \boldsymbol{I}\right] \boldsymbol{h}_{\boldsymbol{l m}} } & =\boldsymbol{J}^{\boldsymbol{T}} \boldsymbol{W}(\boldsymbol{y}-\widehat{\boldsymbol{y}})
\end{aligned}
$$

dimana nilai parameter $\lambda$ merupakan parameter damping yang menentukan pergerakan dari pembaharuan parameter. J merupakan matriks Jacobian $[\partial \hat{y} / \partial \beta]$.

Selama iterasi, besar nilai $\lambda$ dikendalikan oleh ratio $(\rho)$

$$
\begin{aligned}
\rho_{i}\left(\boldsymbol{h}_{\boldsymbol{l m}}\right) & =\frac{\chi^{2}(\beta)-\chi^{2}\left(\beta+\boldsymbol{h}_{\boldsymbol{l m}}\right)}{(\boldsymbol{y}-\hat{\boldsymbol{y}})^{\boldsymbol{T}} \boldsymbol{W}(\boldsymbol{y}-\hat{\boldsymbol{y}})-\left(\boldsymbol{y}-\widehat{\boldsymbol{y}}-\boldsymbol{J} \boldsymbol{h}_{\boldsymbol{l m}}\right)^{\boldsymbol{T}} \boldsymbol{W}\left(\boldsymbol{y}-\hat{\boldsymbol{y}}-\boldsymbol{J} \boldsymbol{h}_{\boldsymbol{l m}}\right)} \\
& =\frac{\chi^{2}(\beta)-\chi^{2}\left(\beta+\boldsymbol{h}_{\boldsymbol{l m}}\right)}{\boldsymbol{h}_{\boldsymbol{l m}}^{\boldsymbol{T}}\left(\lambda_{i} \boldsymbol{h}_{\boldsymbol{l m}}+\boldsymbol{J}^{\boldsymbol{T}} \boldsymbol{W}(\boldsymbol{y}-\widehat{\boldsymbol{y}}(\boldsymbol{\beta}))\right)}
\end{aligned}
$$

Jika dalam iterasi $\rho_{i}\left(h_{l m}\right)>\varepsilon=10^{-6}$, berarti $\chi^{2}(\beta)>\chi^{2}\left(\beta+h_{l m}\right)$ maka estimator $\beta+h_{l m}$ lebih baik daripada $\beta$, kemudian $\beta$ akan digantikan oleh $\beta+h_{l m}$. Apabila nilai $\rho_{i}\left(h_{l m}\right)<\varepsilon=10^{-6}$ maka nilai $\beta+h_{l m}$ lebih buruk dari $\beta$, sehingga nilai $\lambda$ perlu ditingkatkan agar langkah lebih dekat (Primandari, 2016).

\subsection{Ukuran Kesalahan}

Metode peramalan bertujuan untuk menghasilkan ramalan yang optimum dengan tidak memiliki tingkat kesalahan yang besar. Salah satu cara untuk mengetahui seberapa akurat peramalan yang dihasilkan atau seberapa kecil penyimpangan yang dialami yaitu dengan menghitung nilai Mean Absolute Perrcentage Error (MAPE). MAPE menyatakan persentase kesalahan terlalu tinggi atau terlalu rendah berdasarkan persentase kesalahan hasil dari peramalan terhadap permintaan aktual selama periode tertentu. Rumus MAPE secara umum dapat dituliskan sebagai berikut:

$$
M A P E=\frac{1}{n} \sum_{i=1}^{n} \frac{\left|X_{n}-\widehat{X_{n}}\right|}{X_{n}} \times 100 \%
$$

\section{METODE PENELITIAN}

Data yang digunakan dalam penelitian ini jumlah wisatawan nusantara dan mancanegara yang berkunjung ke daya tarik wisata di Jawa Tengah yang terdiri dari data bulanan selama 7 tahun (168 data) terhitung mulai bulan Januari 2012 sampai dengan Desember 2018. Data ini diperoleh dari website Dinas Kepemudaan Olahraga dan Pariwisata Provinsi Jawa Tengah (sisdaporapar.jateng.prov.go.id).

Pengolahan data pada penelitian ini menggunakan bantuan software $R$ 3.6.1 dan Microsoft Excel 2010. Tahapan analisis pada penelitian ini adalah sebagai berikut

\subsection{Tahapan Perhitungan dan Pembuatan Plot Peramalan B-DES}


1. Melakukan input data untuk membuat fungsi (function) untuk peramalan metode B-DES dengan melakukan inisialisasi pada $\mathrm{S}_{1}{ }^{\prime}=\mathrm{MA}(\mathrm{T})$ dan $\mathrm{S}_{1}$ "=MA(T) yang selanjutnya disebut sebagai B-DES(T).

2. Menyusun fungsi B-DES dimana fungsi dilanjutkan dengan melakukan perulangan (looping) untuk rumus B-DES pada persamaan (2) sampai dengan (6) dan dilanjutkan dengan mengoreksi kesalahan fungsi B-DES dengan memasukkan nilai beta.

3. Membuat function error untuk nilai MAPE berdasarkan fungsi peramalan metode BDES dengan menggunakan persamaaan (20) dilanjutkan dengan mengoreksi kesalahan function error.

4. Melakukan optimasi parameter dengan menggunakan algoritma Levenberg-Marquardt (LM) dengan bantuan package library (minpack.lm).

5. Melakukan peramalan B-DES dengan memasukkan nilai parameter hasil optimasi (parameter optimum).

6. Melakukan perhitungan MAPE optimum B-DES

7. Melakukan input data plot B-DES untuk membuat plot yang terdiri dari nilai peramalan hasil dari parameter optimum B-DES dengan data jumlah wisatawan yang dilihat berdasarkan waktu dikeluarkan jumlah wisatawan tersebut (month).

\subsection{Tahapan Perhitungan dan Pembuatan Plot Peramalan B-WEMA}

1. Melakukan input data untuk membuat fungsi (function) untuk peramalan metode BWEMA dengan melakukan inisialisasi pada $S_{1}{ }^{\prime}=W M A(T)$ dan $S_{1}$ "=WMA(T) yang selanjutnya disebut sebagai B-WEMA(T).

2. Membuat fungsi B-WEMA dimana fungsi dilanjutkan dengan melakukan perhitungan perulangan (looping) untuk rumus B-WEMA pada persamaan (7) sampai dengan (13) dan dilanjutkan dengan mengoreksi kesalahan fungsi B-WEMA dengan memasukkan nilai beta.

3. Membuat function error untuk nilai MAPE berdasarkan fungsi peramalan metode BWEMA dengan menggunakan persamaaan (20) dilanjutkan dengan mengoreksi kesalahan function error.

4. Melakukan optimasi parameter dengan menggunakan algoritma Levenberg-Marquardt (LM) dengan bantuan package library(minpack.lm).

5. Melakukan peramalan B-WEMA dengan memasukkan nilai parameter hasil optimasi (parameter optimum).

6. Melakukan perhitungan MAPE optimum B-WEMA.

7. Melakukan input data plot B-WEMA untuk membuat plot yang terdiri dari nilai peramalan hasil dari parameter optimum B-DES dengan data jumlah wisatawan yang dilihat berdasarkan waktu dikeluarkan jumlah wisatawan tersebut (month).

\section{HASIL DAN PEMBAHASAN}

Dalam bagian ini, kita dapat membandingkan hasil perhitungan antara metode B-DES dan B-WEMA. Sebelum itu optimasi parameter beta perlu dilakukan pada metode B-DES dan B-WEMA. Optimasi Levenberg-Marquardt dilakukan dengan bantuan package library(minpack.lm) yang tersedia pada software R. Hasil perubahan parameter sebelum dan sesudah dilakukan optimasi dapat dilihat pada Tabel 1 berikut ini. 
Tabel 1 Hasil Optimasi Parameter Metode B-DES dan B-WEMA

\begin{tabular}{lcc}
\hline \multirow{2}{*}{ Metode } & \multicolumn{2}{c}{ Nilai Parameter } \\
\cline { 2 - 3 } & Sebelum Optimasi & Sesudah Optimasi \\
\hline B-DES Nusantara & 0,2 & 0,21944386 \\
B-DES Mancanegara & 0,2 & 0,26213368 \\
B-WEMA Nusantara & 0,2 & 0,2919441 \\
B-WEMA Mancaegara & 0,2 & 0,26213367 \\
\hline
\end{tabular}

Setelah didapatkan nilai parameter optimum dari masing-masing metode, kemudian dilanjutkan untuk meramalkan jumlah wisatawan untuk 12 periode ke depan. Hasil peramalan dapat dilihat pada Tabel 2.

Tabel 2 Hasil Peramalan Metode B-DES dan B-WEMA pada Data Jumlah Wisatawan Nusantara

\begin{tabular}{ccccccc}
\hline \multirow{2}{*}{ Periode } & Wisatawan & \multicolumn{2}{c}{ Hasil Peramalan } & \multirow{2}{*}{ Wisatawan } & \multicolumn{2}{c}{ Hasil Peramalan } \\
\cline { 3 - 4 } \cline { 6 - 7 } & Nusantara & B-DES & B-WEMA & Mancanegara & B-DES & B-WEMA \\
\hline $2018-01$ & 4097946 & 3429645 & 3429645 & 36594 & 53657,6059 & 53657,6062 \\
$2018-02$ & 2666503 & 3441396 & 3441395 & 53413 & 51879,0707 & 51879,0712 \\
$2018-03$ & 3612377 & 3453147 & 3453146 & 49675 & 50100,5356 & 50100,5361 \\
$2018-04$ & 4451888 & 3464897 & 3464896 & 48322 & 48322,0005 & 48322,0010 \\
$2018-05$ & 3491058 & 3476648 & 3476647 & 43492 & 46543,4653 & 46543,4660 \\
$2018-06$ & 7236124 & 3488398 & 3488397 & 44400 & 44764,9302 & 44764,9309 \\
$2018-07$ & 4171245 & 3500149 & 3500148 & 68110 & 42986,3951 & 42986,3959 \\
$2018-08$ & 3375748 & 3511900 & 3511898 & 123538 & 41207,8599 & 41207,8608 \\
$2018-09$ & 3512484 & 3523650 & 3523649 & 58998 & 39429,3248 & 39429,3258 \\
$2018-10$ & 3270112 & 3535401 & 3535399 & 34525 & 37650,7896 & 37650,7907 \\
$2018-11$ & 3375002 & 3547152 & 3547150 & 59993 & 35872,2545 & 35872,2556 \\
$2018-12$ & 5683120 & 3558902 & 3558900 & 56063 & 34093,7194 & 34093,7206 \\
\hline
\end{tabular}

Terlihat dari hasil peramalan pada metode B-DES dan B-WEMA dimana nilai peramalan yang diperoleh tidak jauh berbeda. Untuk lebih jelasnya, hasil perbandingan peramalan dalam bentuk grafik dapat dilihat pada Gambar 1 dan Gambar 2. 


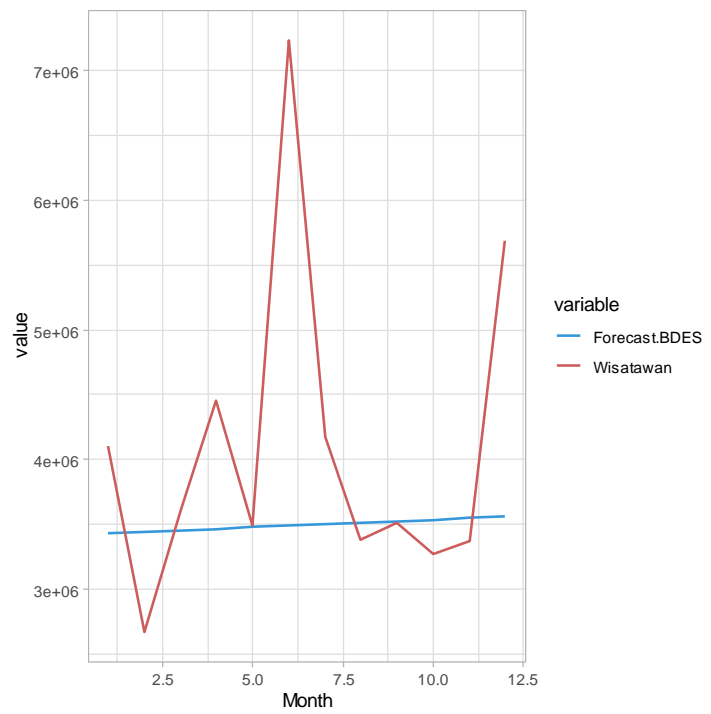

Peramalan B-DES(12) data nusantara

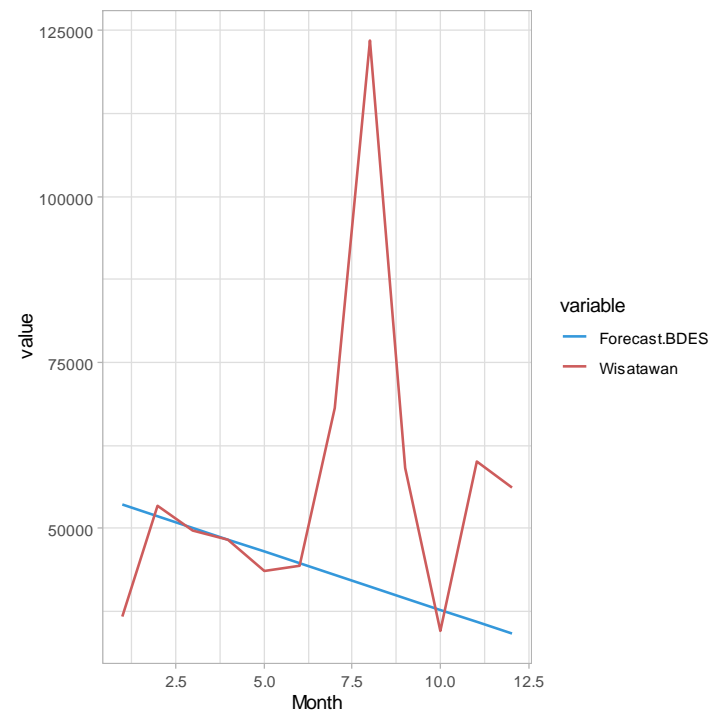

Peramalan B-DES(12) data mancanegara

Gambar 1 Grafik Hasil Peramalan metode B-DES(12)

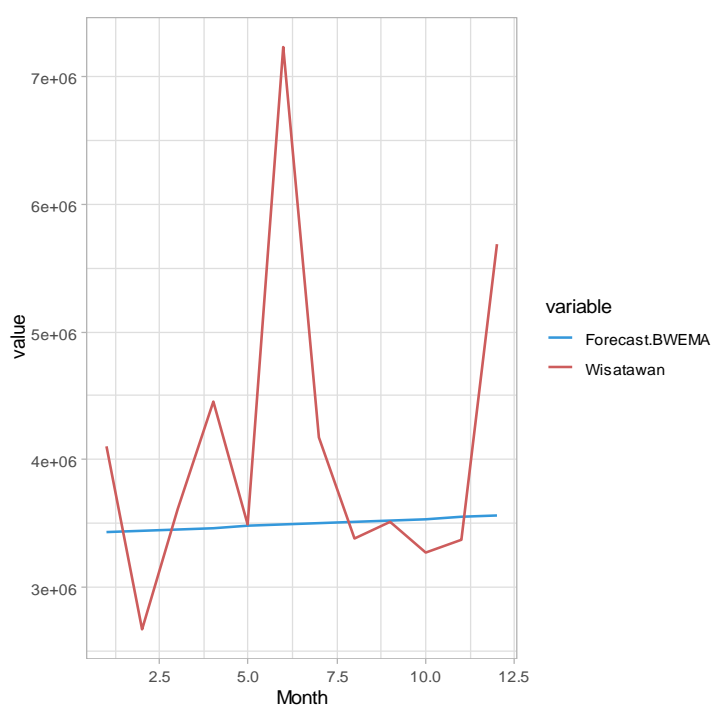

Peramalan B-WEMA(12) data nusantara

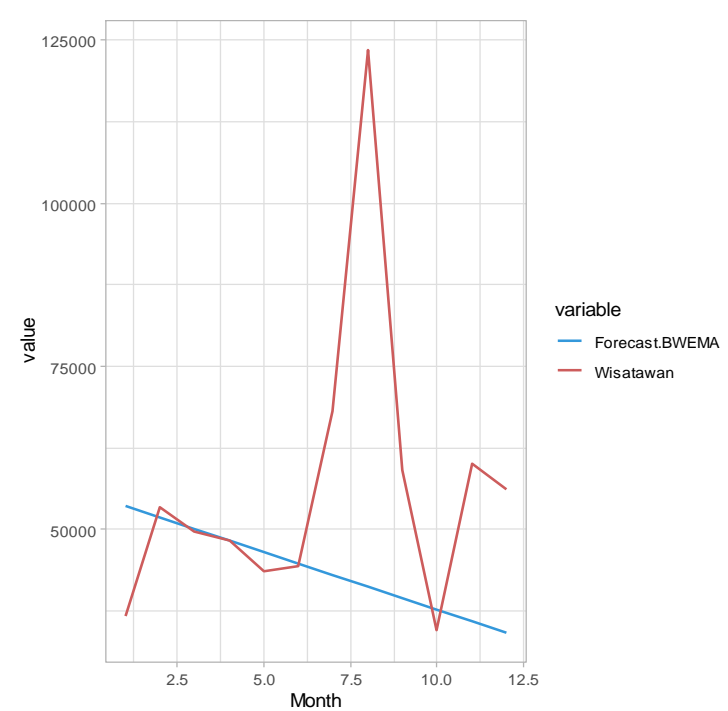

Peramalan B-WEMA(12) data mancanegara Gambar 2 Grafik Hasil Peramalan metode B-WEMA(12)

Terlihat dari Gambar 1 dan Gambar 2 data nusantara terjadi lonjakan pada bulan Juni yang disebabkan oleh libur hari Raya Idul Fitri yang berbarengan dengan libur semester sekolah, sehingga menyebabkan banyak masyarakat yang melakukan perjalanan wisata. Sedangkan untuk data wisatawan mancanegara, pada bulan Agustus terjadi lonjakan jumlah wisatawan karena dampak pelemahan rupiah terhadap dolar AS. Selain itu masa liburan musim panas juga sedang berlangsung di Eropa dimulai dari bulan Juli hingga Agustus. Kurva yang ditampilkan dari kedua metode memiliki pola yang sama antara metode B-DES dan B-WEMA Untuk hasil terbaik, dapat dilihat berdasarkan nilai error terkecil dari MAPE 
out sample pada masing-masing metode. Hasil perhitungan MAPE in sample dan out sample dapat dilihat pada Tabel 3 dan Tabel 4.

Tabel 3 Hasil Perhitungan MAPE pada Data Wisatawan Nusantara

\begin{tabular}{lcc}
\hline \multicolumn{1}{c}{ Metode } & MAPE in sample & MAPE out sample \\
\hline B DES $(\beta=0,2)$ & $31,48988 \%$ & $16,28453 \%$ \\
B DES dengan LM $(\beta=0,21944386)$ & $31,94857 \%$ & $16,26516 \%$ \\
B WEMA $(\beta=0,2)$ & $31,64308 \%$ & $16,28451 \%$ \\
B WEMA dengan LM $(\beta=0,219441)$ & $32,09665 \%$ & $16,26515 \%$ \\
\hline
\end{tabular}

Tabel 4 Hasil Perhitungan MAPE pada Data Wisatawan Mancanegara

\begin{tabular}{lcc}
\hline \multicolumn{1}{c}{ Metode } & MAPE in sample & MAPE out sampel \\
\hline B-DES $(\beta=0,2)$ & $27,03343 \%$ & $27,19141 \%$ \\
B-DES dengan LM $(\beta=0,26213368)$ & $27,28474 \%$ & $23,61278 \%$ \\
B-WEMA $(\beta=0,2)$ & $27,26220 \%$ & $27,19132 \%$ \\
B-WEMA dengan LM $(\beta=0,26213367)$ & $27,52981 \%$ & $23,61278 \%$ \\
\hline
\end{tabular}

Seperti yang dapat terlihat pada Tabel 3, dengan menggunakan $\beta=0,2$ metode BWEMA memiliki nilai MAPE out sample yang lebih kecil yaitu 16,28451\% dibandingkan dengan metode B-DES yaitu 16,28453\%. Sedangkan dengan menggunakan parameter optimasi LM metode B-WEMA memperoleh nilai MAPE out sample yang lebih kecil pula, yaitu sebesar 16,26515\% dibandingkan dengan metode B-DES. Metode B-DES dengan optimasi LM memiliki nilai MAPE out sample sebesar 16,26516\%.

Pada Tabel 4 , dengan menggunakan $\beta=0,2$ metode B-WEMA memiliki nilai MAPE out sample yang lebih kecil yaitu $27,19132 \%$ dibandingkan dengan metode B-DES yaitu $27,19141 \%$. Sedangkan menggunakan optimasi LM, metode B-DES dan metode B-WEMA memiliki nilai MAPE out sample yang sama yaitu sebesar 23,61278\%.

\section{KESIMPULAN}

Penerapan Levenberg-Marquardt (LM) pada metode B-DES dan B-WEMA menghasilkan parameter optimal untuk data jumlah wisatawan nusantara metode B-DES adalah 0,21944386 dan metode B-WEMA adalah 0,219441. Sedangkan untuk data jumlah wisatawan mancanegara diperoleh nilai parameter optimal metode B-DES adalah 0,26213368 dan metode B-WEMA adalah 0,26213367. Perbandingan nilai MAPE out sample pada metode B-DES dan B-WEMA dilakukan untuk melihat metode terbaik dengan nilai error terkecil. Untuk data jumlah wisatawan nusantara, B-WEMA dengan optimasi LM memiliki nilai MAPE out sample terkecil yaitu 16,26515\% dimana nilai ini memiliki selisih yang sedikit dengan metode B-DES menggunakan optimasi LM yang memiliki nilai MAPE out sample 16,2516\%. Sedangkan untuk data jumlah wisatawan mancanegara metode BDES dengan optimasi LM dan B-WEMA dengan optimasi LM memiliki nilai MAPE out sample yang sama yaitu $23,61278 \%$. Hal ini berarti bahwa kedua metode tersebut memiliki tingkat akurasi peramalan yang baik pada data jumlah wisatawan nusantara dan tingkat akurasi yang cukup pada data jumlah wisatawan mancanegara. 


\section{DAFTAR PUSTAKA}

Budiasih. 2009. Metode Levenberg-Marquardt Untuk Masalah Kuadrat Terkecil Nonlinear. Seminar Nasional Matematika dan Pendidikan Matermatika. Yogyakarta: Universitas Negeri Yogyakarta.

Gavin, H.P. 2019. The Levenberg-Marquardt Method for Nonlinier Least Square CurveFitting Problems. Department of Civil and Environmental Engineering Duke University.

Hansun, S. 2013. A New Approach of Moving Average Method in Time Series Analysis. International Conference on New Media (CoNMedia) (hal. 1-4). Indonesia: Proc. of the 2013 IEEE International Conference on New Media

Hansun, S. 2016. A New Approach of Brown's Double Exponential Smoothing Method in Time Series Analysis. Balkan Journal of Electrical \& Computer Engineering (BAJECE), 75-78.

Makridakis, S., McGee, V.E., \& Wheelwright, S.C. 1999. Metode dan Aplikasi Peramalan. Edisi 2 Jilid 1. Jakarta : Penerbit Erlangga.

Primandari, A. H. 2016. Grey Double Exponential Smoothing dengan Optimasi LevenbergMarquardt untuk Peramalan Volume Penumpang di Bandara Soekarno-Hatta. Jurnal Derivt Volume 3 No. 2 , 25-39. 